\title{
Experimental and Numerical Study on Hydromechanical Coupled Deformation Behavior of Beishan Granite considering Permeability Evolution
}

\author{
Z. H. Wang $\mathbb{D}^{1,2}$ W. G. Ren, ${ }^{3}$ Y. L. Tan, ${ }^{1,2}$ and Heinz Konietzky ${ }^{4}$ \\ ${ }^{1}$ State Key Laboratory of Mining Disaster Prevention and Control Cofounded by Shandong Province and the Ministry of Science \\ and Technology, Shandong University of Science and Technology, Qingdao Shandong 266590, China \\ ${ }^{2}$ College of Energy and Mining Engineering, Shandong University of Science and Technology, Qingdao Shandong 266590, China \\ ${ }^{3}$ School of Mechanics and Civil Engineering, China University of Mining and Technology, Beijing 100083, China \\ ${ }^{4}$ Geotechnical Institute, TU Bergakademie Freiberg, Gustav-Zeuner-Str. 1, 09596 Freiberg, Germany
}

Correspondence should be addressed to Z. H. Wang; skd996340@sdust.edu.cn

Received 25 May 2020; Revised 12 July 2020; Accepted 21 July 2020; Published 5 August 2020

Academic Editor: Qiqing Wang

Copyright (c) 2020 Z. H. Wang et al. This is an open access article distributed under the Creative Commons Attribution License, which permits unrestricted use, distribution, and reproduction in any medium, provided the original work is properly cited.

Beishan granite is a potential host rock for a high-level radioactive waste (HLW) repository in China. Understanding the hydromechanical (HM) behavior and permeability evolution of Beishan granite is important for the HLW repository safety. Therefore, the granite of Beishan in Gansu province was studied. HM coupled tests are carried out on Beishan granite under different pore pressures. The results show that the initial pressure difference has little influence on permeability measurement before dilatancy starts. However, after onset of dilatancy, the permeability increases with the increasing initial pressure difference. The initial permeability of Beishan granite is about $10^{-18} \mathrm{~m}^{2}$ under a confining pressure of $20 \mathrm{MPa}$. In the initial loading phase, the permeability shows a relatively large reduction. Then, the permeability almost keeps constant until dilatancy starts. From dilatancy point to peak stress, permeability increases linearly with volumetric strain. The proposed permeability evolution rule is implemented into a numerical code to perform HM coupled simulations. The simulation results show that the damaged zone first appears at the model boundary and then extends to the inside, forming high volumetric strain areas. And it provides seepage channels for fluid flow. The macroscopic fracture patterns indicate that pore pressure accelerates rock degradation during HM coupling. The obtained results help to understand the damage mechanisms of granite caused by pore pressures and are of great importance for the safety of a HLW repository.

\section{Introduction}

Disposal of high-level radioactive waste (HLW) deep underground is one of the most challenging research subjects in rock engineering. The biggest difficulty is the proof of safe and long-term isolation of the HLW from the biosphere. Granite, characterized by high strength and low permeability, is one of the preferred host rocks for geological disposal of HLW. China plans to build a HLW repository in the granite strata of Beishan, Gansu Province $[1,2]$. Therefore, the understanding of the hydromechanical (HM) coupled behavior and permeability evolution of Beishan granite is of great significance to ensure the long-term safety of the HLW repository.
As a heterogeneous material, rock contains microcracks. The failure process of rock associated with crack propagation has been well studied [3-8]. On the other hand, cracks provide seepage channels for fluid flow. The fluid flow in the crack network will accelerate the rock failure process, which has influence on rock strength and deformation [9-12]. Therefore, after years of research, the permeability evolution during the rock failure process has gradually attracted the attention of researchers. Brace et al. [13] and Zoback et al. [14] studied the permeability of Westerly granite. Their results indicate that permeability has strong dependence on effective pressure and increases gradually after dilatancy threshold. Hydrostatic compression and triaxial compression tests were conducted on 


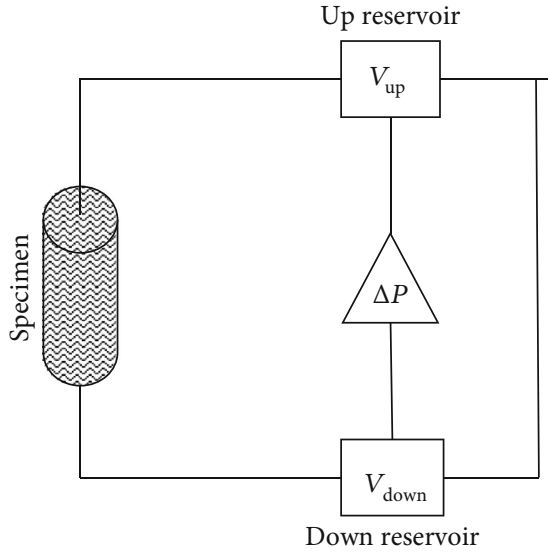

(a)

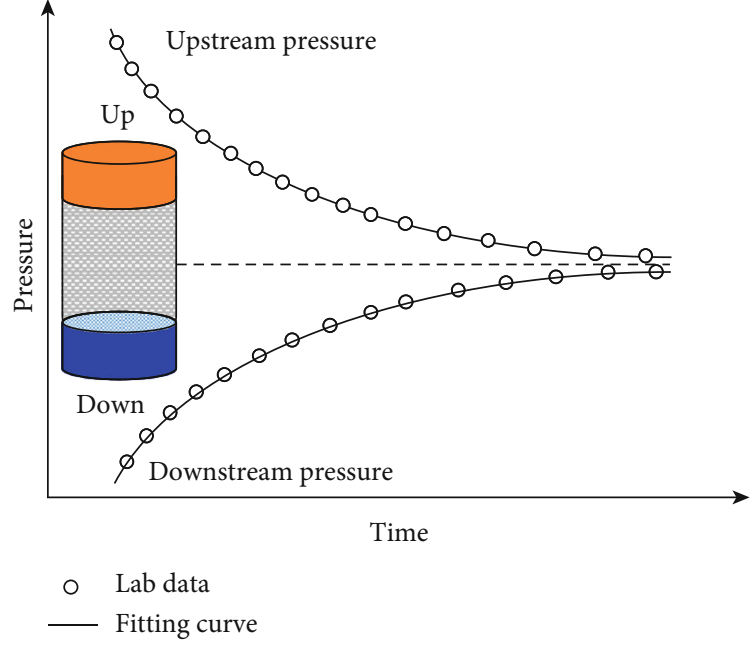

(b)

FIgURE 1: Simplified schematic of the transient pulse method: (a) testing system and (b) measuring pressure decay over time.

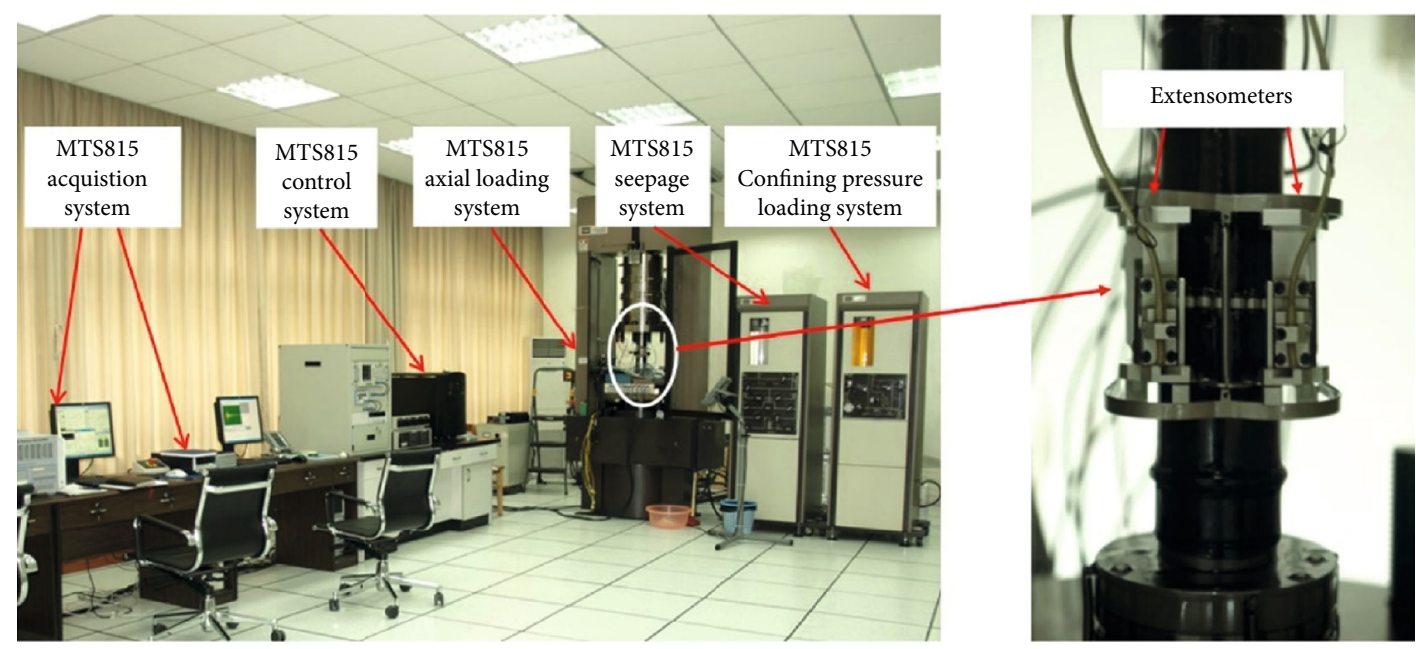

FIGURE 2: Rock mechanics experimental system of MTS815 and installation of sample.

Inada granite by Kiyama et al. [15]. The results show that permeability increases proportionally to the dilatation between the onset of dilatancy and the peak strength. Liu et al. [16] investigated the permeability evolution of granite gneiss during triaxial creep tests. They demonstrate that the permeability remains stable in the steady creep stage and increases rapidly in the accelerated creep stage. For granite, Chen [17] revealed that the permeability decreases when confining pressure is larger and increases when pore water pressure is larger under compressive stress conditions. Yi et al. [18], Heiland and Raab [19], Alam et al. [20], and Zhang et al. [21] studied permeability evolution of different rock types under compression. The results show similar permeability evolution trends, in which the permeability decreases at the stage of volumetric compaction and increases at the stage of volumetric dilation.

On the other hand, important progress has been made in numerical simulation of HM coupled processes in rocks, especially in the DECOVALEX project $[22,23]$. A flowstress-damage (FSD) coupling model considering permeabil- ity evolution is proposed by Tang et al. [24]. And this FSD model is used to investigate the behavior of fluid flow and damage evolution under hydraulic conditions. Rutqvist et al. [25] linked two codes-TOUGH2 and FLAC ${ }^{3 \mathrm{D}}$-for analysis of coupled THM processes, in which the coupling module containing nonlinear stress versus permeability functions is taken into account. Tan and Konietzky [26] proposed a micromechanical numerical model to simulate the HM coupled behavior of granite at the grain-sized level. It reveals the importance of tensile micro cracks for enhanced permeability, and linear correlations between volumetric strain and permeability are observed by numerical simulations. $\mathrm{Lu}$ et al. [27] presented a coupled continuum-based HM modeling approach using a two-scale conceptual model representing realistic rock material containing microfractures. This model is validated against failure under compression and replicates typical AE characteristics and permeability evolution.

This paper presents HM coupling tests carried out on Beishan granite under different pore pressures. The influence 
TABLE 1: Permeability test results for specimen BSS-1 for three different initial pressure differences.

\begin{tabular}{|c|c|c|c|c|}
\hline \multirow{2}{*}{ Axial strain (\%) } & \multirow{2}{*}{ Axial stress $(\mathrm{MPa})$} & \multicolumn{3}{|c|}{ Permeability $\left(10^{-18} \mathrm{~m}^{2}\right)$} \\
\hline & & $3.4 \mathrm{MPa}$ & $5.4 \mathrm{MPa}$ & 7.4 MPa \\
\hline 0 & 0 & 3.77 & 2.97 & 2.33 \\
\hline 0.386 & 38.6 & 1.05 & 1.30 & 1.34 \\
\hline 0.629 & 79.3 & 1.03 & 1.12 & 1.29 \\
\hline 0.855 & 123.8 & 0.55 & 1.08 & 1.26 \\
\hline 1.066 & 165.6 & 0.94 & 1.29 & 1.65 \\
\hline 1.240 & 201.8 & 1.45 & 1.92 & 2.36 \\
\hline 1.528 & 256.6 & 3.43 & 5.30 & 7.54 \\
\hline 2.337 & 81.8 & 72.74 & 55.31 & 59.57 \\
\hline
\end{tabular}

TABle 2: Permeability test results for specimen BSS-2 for three different initial pressure differences.

\begin{tabular}{|c|c|c|c|c|}
\hline \multirow{2}{*}{ Axial strain (\%) } & \multirow{2}{*}{ Axial stress (MPa) } & \multicolumn{3}{|c|}{ Permeability $\left(10^{-18} \mathrm{~m}^{2}\right)$} \\
\hline & & $3.4 \mathrm{MPa}$ & $5.4 \mathrm{MPa}$ & $7.4 \mathrm{MPa}$ \\
\hline 0 & 0 & 1.32 & 1.24 & 0.64 \\
\hline 0.414 & 48.7 & 0.71 & 0.66 & 0.66 \\
\hline 0.716 & 106.1 & 0.78 & 0.50 & 0.47 \\
\hline 0.940 & 150.1 & 0.48 & 0.56 & 0.48 \\
\hline 1.163 & 200.0 & 0.75 & 0.61 & 0.70 \\
\hline 1.425 & 252.5 & 1.33 & 1.12 & 1.54 \\
\hline 1.855 & 315.6 & 5.81 & 9.86 & 15.36 \\
\hline 2.011 & 79.5 & 13.56 & 16.07 & 17.74 \\
\hline 2.599 & 75.9 & 13.25 & 14.08 & 14.69 \\
\hline
\end{tabular}

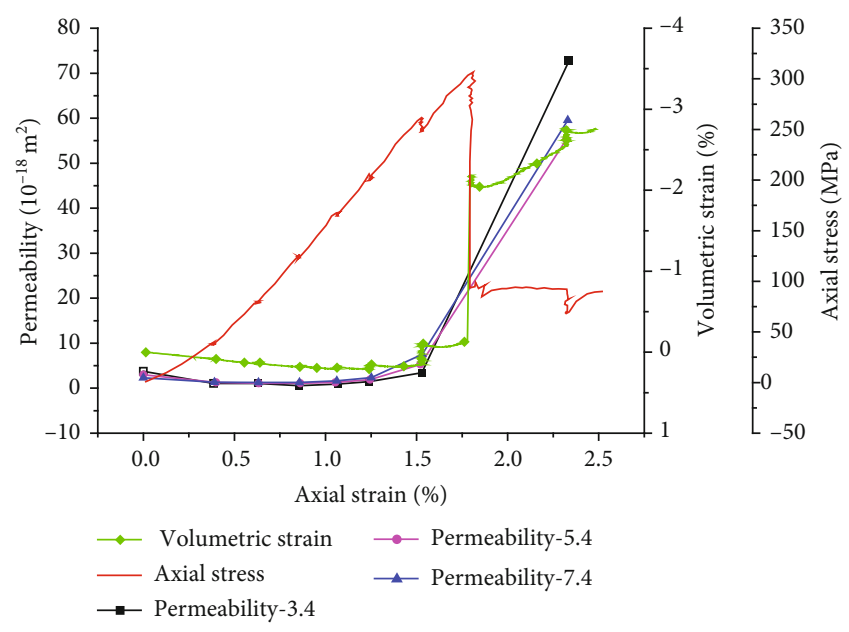

(a)

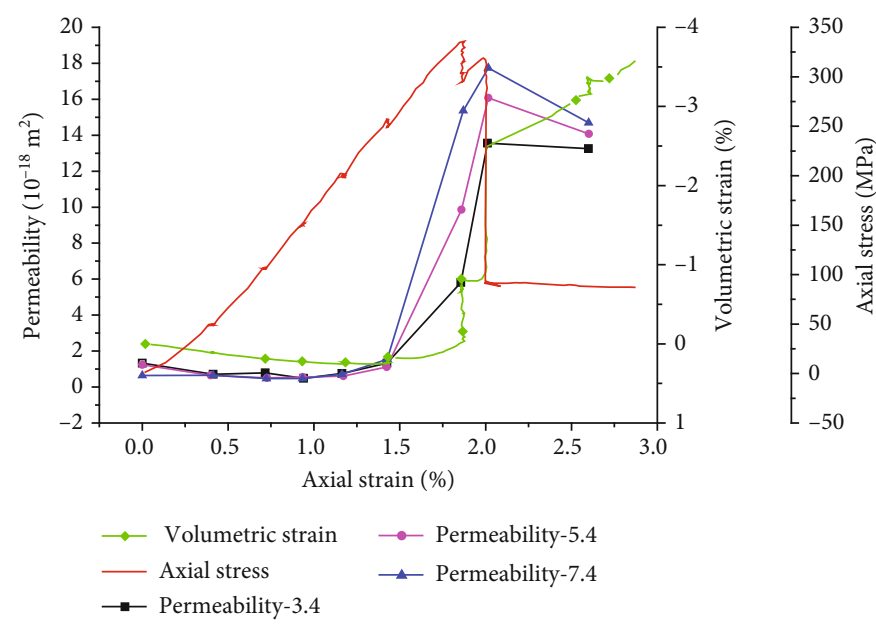

(b)

FIgure 3: Permeability for different initial differential pressures (a) BSS-1 (b) BSS-2.

of initial pressure difference $\left(\triangle P_{0}\right)$ on permeability monitored by the transient pulse method is discussed. The permeability evolution of Beishan granite under compression is revealed. In addition, a heterogeneous numerical model is established to simulate the deformation and damage process under HM coupling considering volumetric strain and permeability evolution.

\section{Permeability Measurements by the Transient Pulse Method}

In most cases, permeability can be measured either by using the constant head method [28, 29] or the transient pulse method [30-33]. However, due to the low permeability of granite, it will take a long time for the fluid to reach a steady 


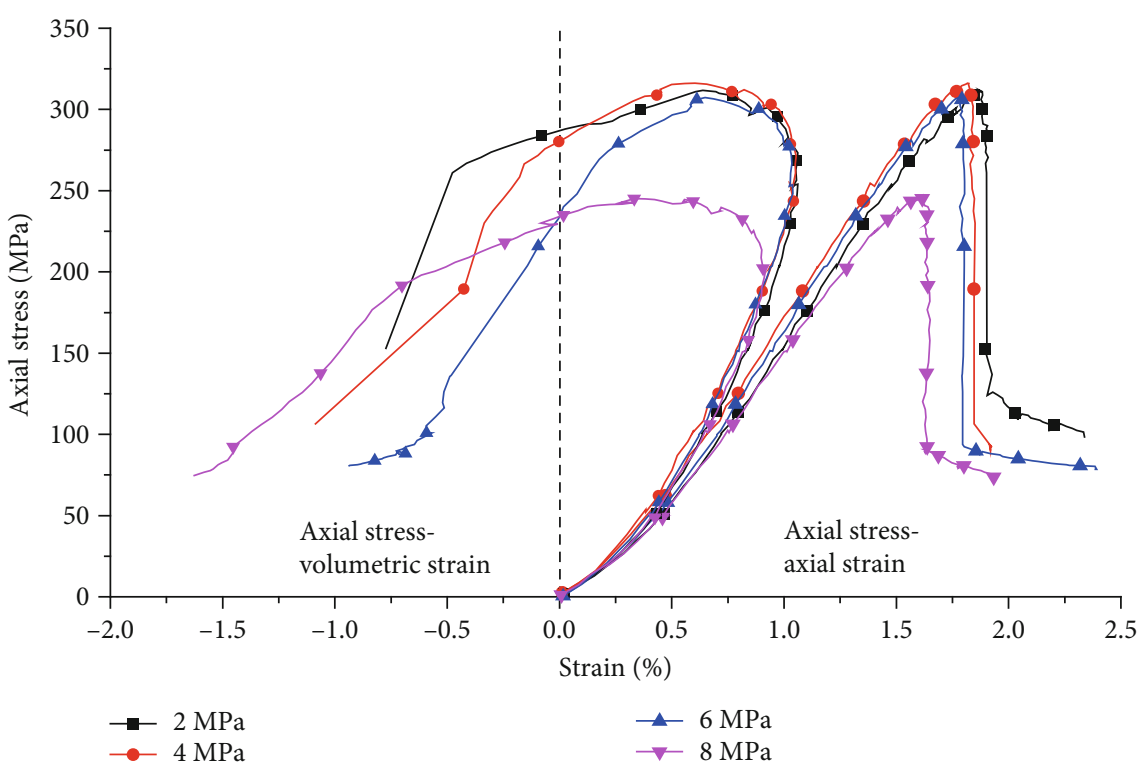

FIGURE 4: Stress strain curves of Beishan granite under different pore pressures [40].

TABle 3: Permeability evolution under different pore pressures.

\begin{tabular}{|c|c|c|c|c|c|c|c|c|c|}
\hline \multirow{2}{*}{ Sample } & \multirow{2}{*}{ Pore pressure $(\mathrm{MPa})$} & \multicolumn{8}{|c|}{ Permeability $/ 10^{-18} \mathrm{~m}^{2}$} \\
\hline & & $1 s \mathrm{t}^{\mathrm{a}}$ & 2nd & $3 \mathrm{rd}$ & 4 th & 5 th & 6th & 7 th & 8 th \\
\hline HM-1 & 2 & 5.8 & 2.78 & 4.91 & 6.5 & $20.29\left(\mathrm{p}^{\mathrm{b}}\right)$ & 22.71 & 22.89 & 25.49 \\
\hline HM-2 & 4 & 1.29 & 0.51 & 0.38 & $1.14(\mathrm{p})$ & 3.04 & 3.74 & 5.38 & - \\
\hline HM-3 & 6 & 0.95 & 0.29 & 0.48 & 1.3 & 2.46 & 5.85 & $10.7(\mathrm{p})$ & 32.78 \\
\hline HM-4 & 8 & 2.29 & 1.48 & 1.77 & 3.84 & 7.03 & 11.51 & $13.17(\mathrm{p})$ & 26.16 \\
\hline
\end{tabular}

a"1st" represents the first time to measure permeability. "P" represents the permeability measured around peak stress.

flow by using the constant head method. Compared with the constant head method, fluid does not need to achieve a steady flow by using the transient pulse method. Therefore, it will consume less time. And the transient method has higher accuracy for low permeability rocks. As a result, in this study, the transient pulse method is used.

The test principle of transient pulse method is shown in Figure 1. At the beginning, a constant pore pressure is maintained in the sample and adjacent upper and lower fluid reservoir. Then, the pressure in the upper reservoir is instantaneously increased and the pressure decay at both reservoirs is monitored. The pressure difference can be described by

$$
\left\{\begin{array}{l}
\frac{P_{u}(t)-P_{d}(t)}{\Delta P_{0}}=\exp (-\alpha t), \\
\alpha=\frac{k A}{\mu \beta L}\left(\frac{1}{V_{u}}+\frac{1}{V_{d}}\right),
\end{array}\right.
$$

with $k$ as permeability $\left(\mathrm{m}^{2}\right), \mu$ as viscosity of fluid (water at $20^{\circ} \mathrm{C}: 10^{-3} \mathrm{~Pa} \cdot \mathrm{s}$ ), $\beta$ as the compression coefficient of fluid (water: $4.53 \times 10^{-10} \mathrm{~Pa}^{-1}$ ), $A$ as cross-sectional area of sample $\left(\mathrm{m}^{2}\right), L$ as the height of the sample $(\mathrm{m}), V_{u}$ as the volume of upper reservoir $\left(\mathrm{m}^{3}\right), V_{d}$ as the volume of the lower reservoir $\left(\mathrm{m}^{3}\right), t$ as the duration time $(\mathrm{s}), P_{\mathrm{u}}(t)$ as the pore pressure of the upper reservoir at time $t(\mathrm{MPa}), P_{\mathrm{d}}(t)$ as the pore pressure of the lower reservoir at time $t(\mathrm{MPa})$, and $\triangle P_{0}$ as the initial differential pressure between upper and lower fluid reservoir (MPa). In general, $V_{u}$ equals $V_{d}$; thus, Equation (1) can be rewritten as

$$
k=\mu \beta V \frac{\ln \left(\Delta P_{0} / P_{f}\right)}{2 t(A / L)},
$$

with $P_{f}$ as the final differential pressure between the upper and lower fluid reservoirs (MPa).

\section{Laboratory Test Settings}

3.1. Preparation of Rock Specimens. The granite samples were taken from the Beishan area, Gansu Province, China. The specimens, with a diameter of $50 \mathrm{~mm}$ and length of $100 \mathrm{~mm}$, were prepared according to ISRM recommendations [34]. If readers want to know the basic properties and components of Beishan granite, please refer to literature $[35,36]$.

3.2. Test Facility. The HM coupled tests were carried out with a MTS815 Flex Test GT (see Figure 2) rock mechanical testing machine. This machine has a maximum loading capacity of $4,700 \mathrm{kN}$ and can supply a maximum confining pressure of $140 \mathrm{MPa}$ [37]. Axial and lateral strains are measured by extensometers. 


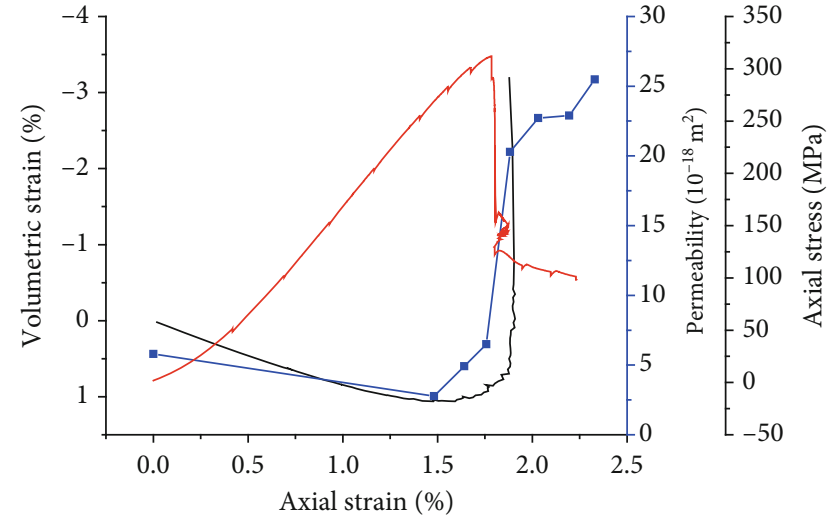

— Volumetric strain (\%)

- Permeability

— Axial stress (MPa)

(a)

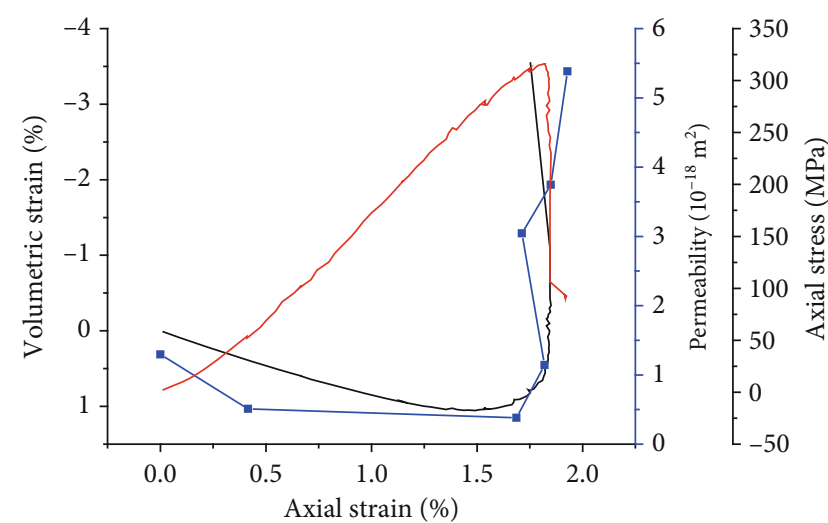

Volumetric strain (\%)

Permeability

_ Axial stress (MPa)

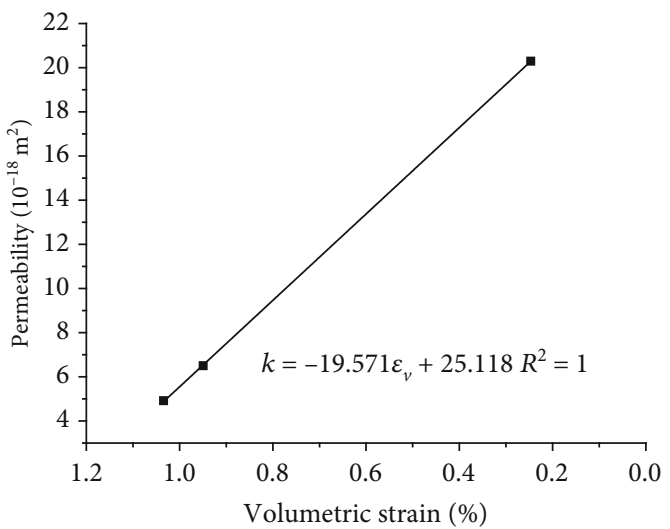

- Permeability

(b)

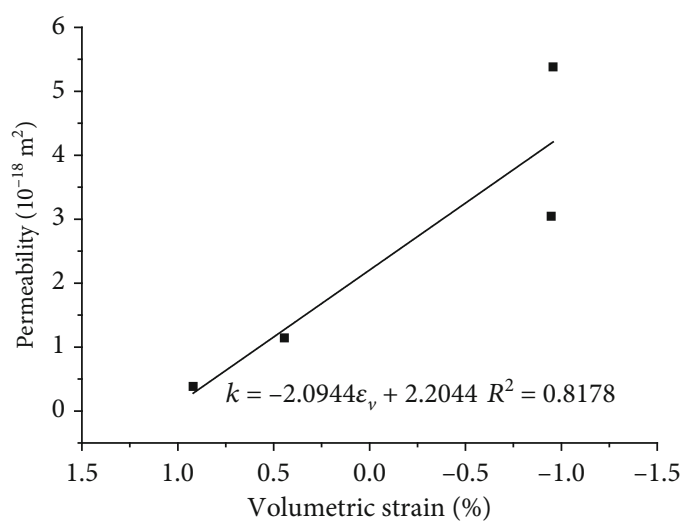

- Permeability

(c)

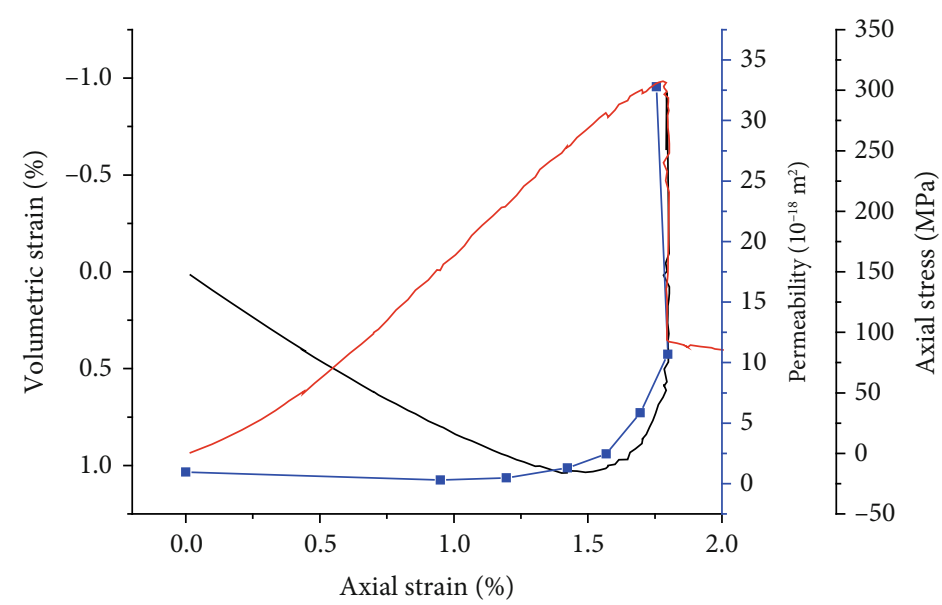

— Volumetric strain (\%)
- Permeability
— Axial stress (MPa)

(e)

Figure 5: Continued. 


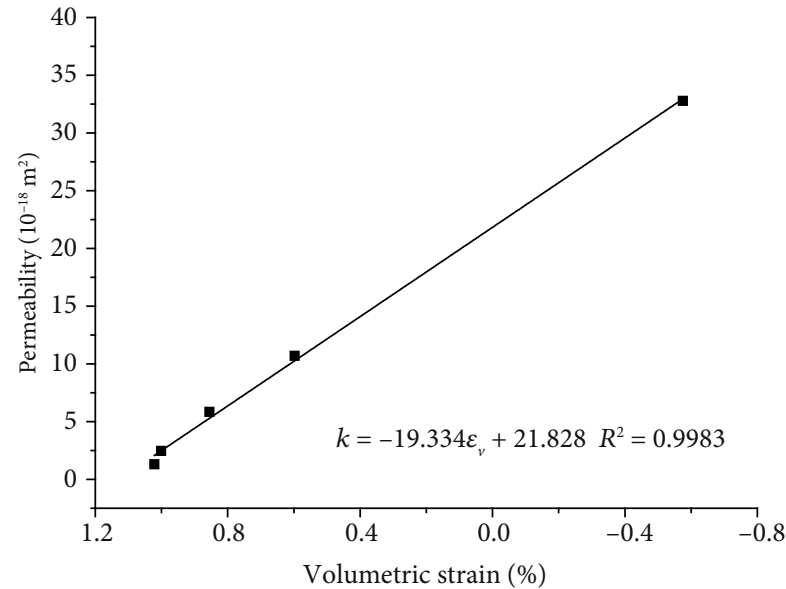

Permeability

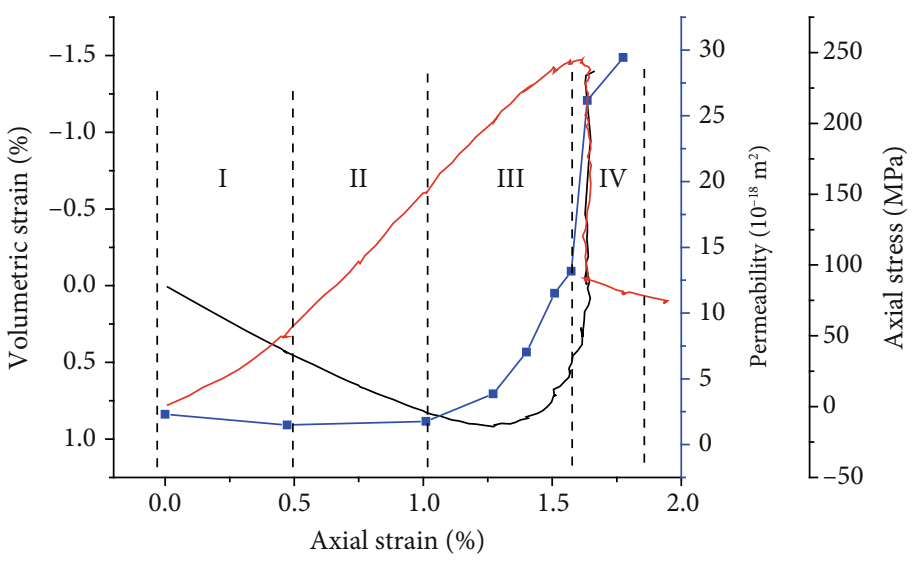

— Volumetric strain (\%)

$\rightarrow$ Permeability $\left(10^{-18} \mathrm{~m}^{2}\right)$

- Axial stress (MPa)

(f)

(g)

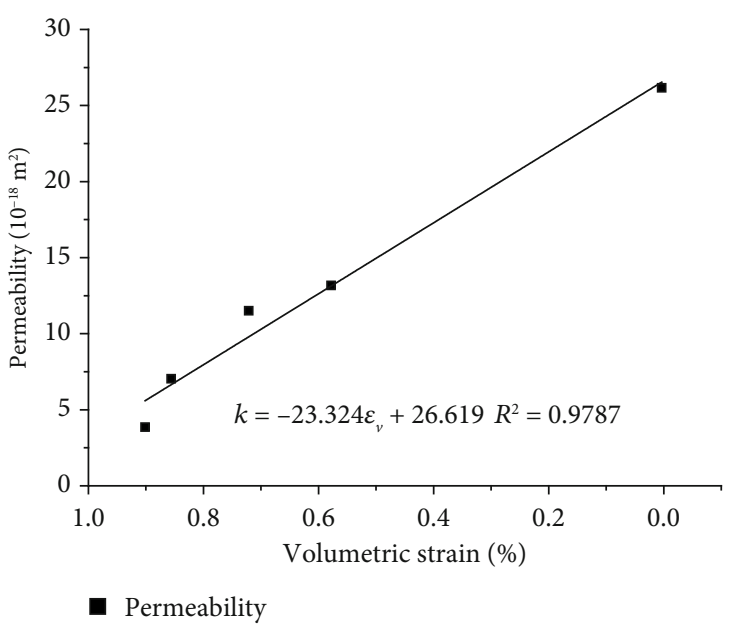

(h)

Figure 5: Permeability evolution of Beishan granite during HM coupling. (a, b) Pore pressure of $2 \mathrm{MPa},(\mathrm{c}, \mathrm{d})$ pore pressure of $4 \mathrm{MPa}$, (e, f) pore pressure of $6 \mathrm{MPa}$, and $(\mathrm{g}, \mathrm{h})$ pore pressure of $8 \mathrm{MPa}$.

3.3. Testing Procedure. Four specimens were prepared for HM coupled testing. Before the tests, the specimens were immersed in water for 72 hours in the vacuum suction device to reach the saturated state [38]. For the HM coupled tests, first, a vertical load of about $2 \mathrm{kN}$ was applied in order to fix the position of the specimen. Then, the desired confining pressure (20 MPa in all HM coupled tests) was reached with a constant loading rate of $0.05 \mathrm{MPa} / \mathrm{s}$ to ensure that the specimen was under uniform hydrostatic stresses [39]. Pore pressures were set to $2,4,6$, and $8 \mathrm{MPa}$, which mirror the maximum potential water pressure at different buried depths in the Beishan region [38]. The desired pore pressure was reached with a constant rate of $1 \mathrm{MPa} / \mathrm{min}$. Afterwards, the axial stress was increased with a constant loading rate of $30 \mathrm{kN} / \mathrm{min}$. During the process of loading, the transient pulse method was used to measure the permeability of Beishan granite at different strain levels. Stress and strain were kept constant during the permeability testing.
In addition, in order to study the influence of initial pressure difference $\left(\triangle P_{0}\right)$ on the transient pulse method, three initial pressure differences were used to measure permeability under the same strain levels during loading. The initial pressure differences were set to $3.4,5.4$, and 7.4 MPa, which is close to the potential water pressure at different buried depths in the Beishan region. And if the initial pressure difference is small, it is not conducive to monitor the pressure decay for Beishan granite because of low permeability. Two specimens (BSS-1 and BSS-2) were used for this task.

\section{Test Results}

4.1. Influence of Initial Pressure Difference $\left(\triangle P_{0}\right)$ on Measurement Results of the Transient Pulse Method. The permeability measured by different initial pressure differences under the same strain levels is shown in Tables 1 and 2 and Figure 3. For a confining pressure of $20 \mathrm{MPa}$, the initial 


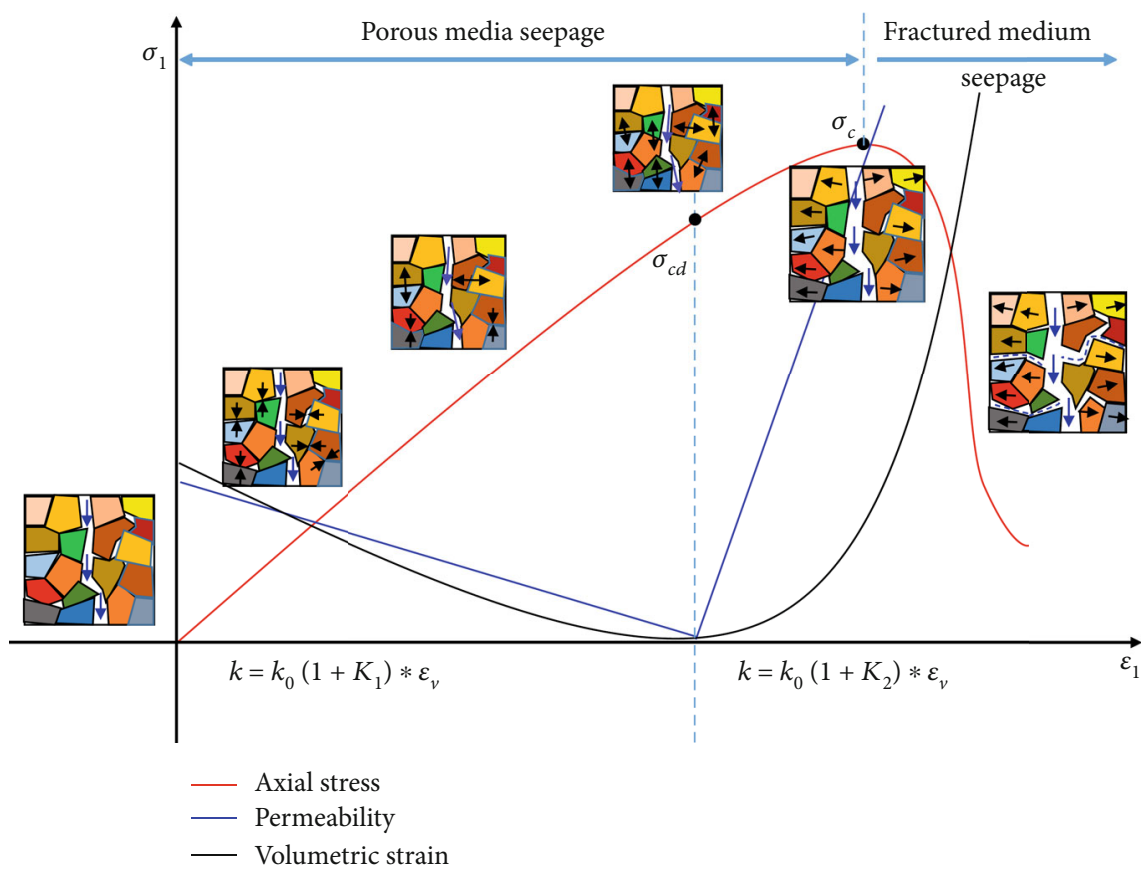

FIGURE 6: Simplified illustration of permeability evolution in HM coupling processes in Beishan granite.

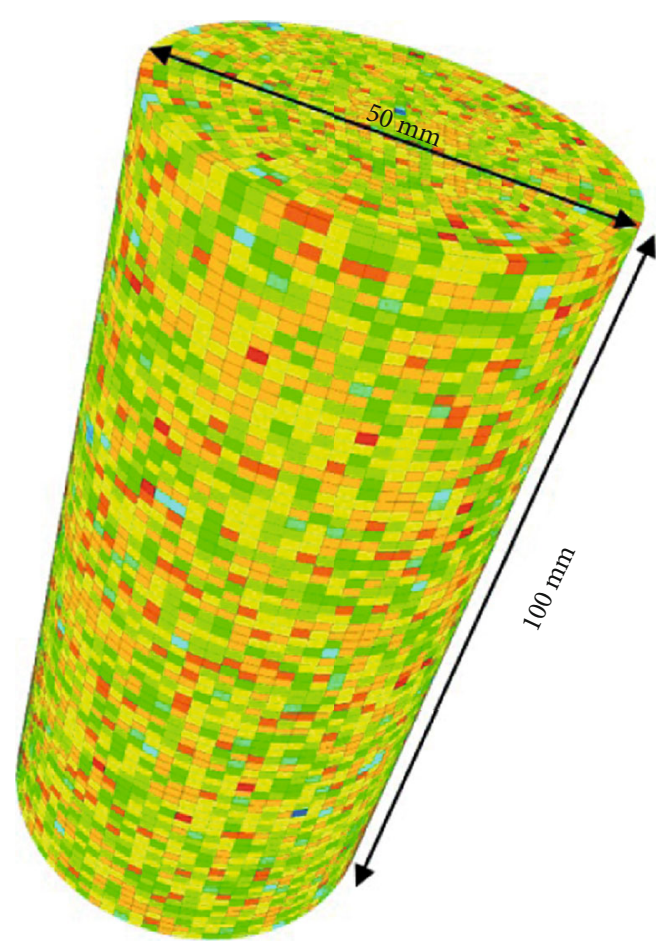

FIGURE 7: Schematic diagram of Beishan granite model.

permeability values measured by different initial pressure differences are quite similar. Because of the unique heterogeneity of each sample, the measured permeability will always show some minor differences.

At the initial stage of loading, due to the closure of micro cracks, permeability decreases. Before onset of dilatancy, the permeability changes little. After onset of dilatancy, permeability is increasing. Also, the permeability increases with the increasing initial pressure difference. For instance, the permeability measured for sample BSS-2 under the initial pressure difference of $7.4 \mathrm{MPa}\left(15.36 \times 10^{-18} \mathrm{~m}^{2}\right)$ around the peak stress is 2.64 times of that measured under the initial pressure difference of $3.4 \mathrm{MPa}\left(5.81 \times 10^{-18} \mathrm{~m}^{2}\right)$. After the peak stress, permeability becomes unstable due to the thrived macro cracks in the sample. The permeability in the post failure region is not discussed in this study.

4.2. Stress Strain Curves of HM Coupled Tests. Figure 4 shows the stress-strain curves of Beishan granite under different pore pressures. With increasing pore pressure, maximum axial strain and peak stress decrease.

4.3. Permeability Evolution of HM Coupled Tests. The permeability measured during HM coupled testing is shown in Table 3 and Figure 5. It can be concluded that the initial permeability of Beishan granite is maintained at about $10^{-18} \mathrm{~m}^{2}$ under the confining pressure $20 \mathrm{MPa}$. On the whole, the permeability first decreases slowly and then increases gradually during loading. The general trend of permeability evolution is the same for different pore pressures.

Taking the pore pressure of $8 \mathrm{MPa}$ as an example, combined with the volumetric strain development, the permeability evolution of Beishan granite under loading can be roughly divided into the following stages. In the first stage (i.e., the initial stage of loading), micro cracks begin to close, which leads to a decrease of sample volume and loss of some seepage channels. Therefore, the decrease of permeability is relatively large compared to the initial permeability (for instance, reduction by $40 \%$ under pore pressure of $4 \mathrm{MPa}$ ). In the second stage, as the axial stress continues to increase, 
TABLE 4: Mechanical parameters of Beishan granite.

\begin{tabular}{lccccccccc}
\hline \multirow{2}{*}{ Elastic modulus $(\mathrm{GPa})$} & \multirow{2}{*}{ Poisson's ratio } & \multirow{2}{*}{ Dilation $\left(^{\circ}\right)$} & \multirow{2}{*}{ Density $\left(\mathrm{kg} / \mathrm{m}^{3}\right)$} & \multicolumn{2}{c}{ Cohesion $(\mathrm{MPa})$} & \multicolumn{2}{c}{ Friction $\left({ }^{\circ}\right)$} & \multicolumn{2}{c}{ Tension $(\mathrm{MPa})$} \\
Initial & Residual & Initial & Residual & Initial & Residual \\
\hline 28.6 & 0.122 & 17 & 2700 & 29.74 & 21.24 & 51 & 31.44 & 7.66 & 0 \\
\hline
\end{tabular}

TABLE 5: Hydraulic parameters of Beishan granite.

\begin{tabular}{lcccc}
\hline Fluid modulus $(\mathrm{GPa})$ & Fluid density $\left(\mathrm{kg} / \mathrm{m}^{3}\right)$ & Initial permeability $\left(\mathrm{m}^{2}\right)$ & Porosity $(\%)$ & Saturation \\
\hline 2.2 & 1000 & $2.58 \times 10^{-18}$ & 0.02 & 1 \\
\hline
\end{tabular}

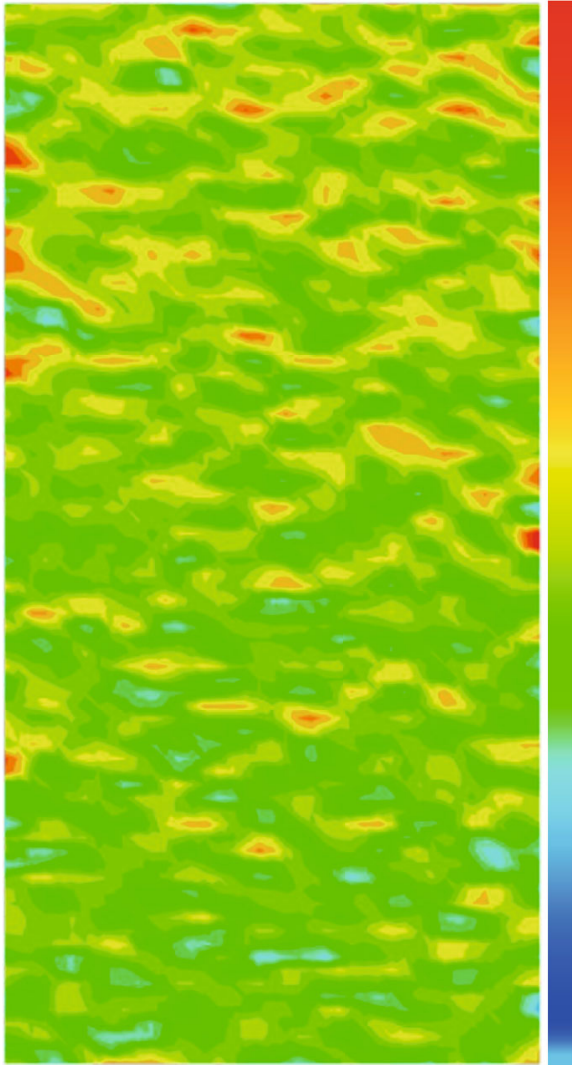

(a)
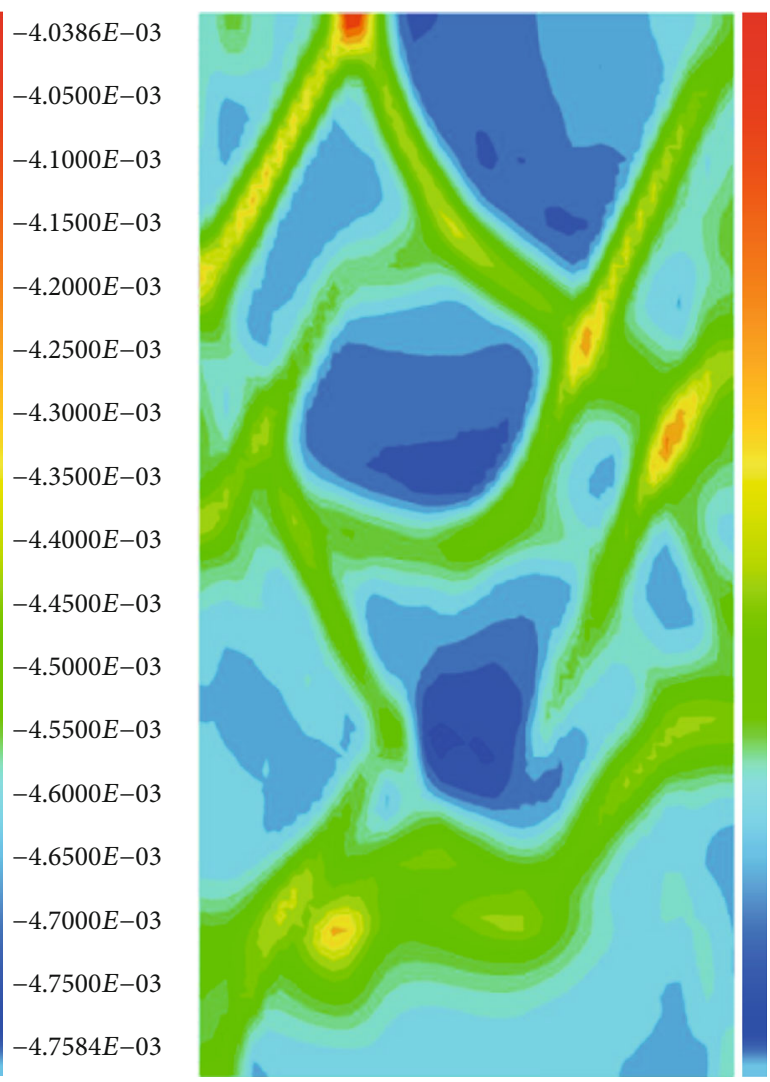

(b)

FIGURE 8: Volumetric strain for confining pressure of $20 \mathrm{MPa}$ (a) compressed stage and (b) damaged stage.

the volume of the specimen decreases. But there is possibility that new micro cracks are generated. Thus, the permeability almost keeps constant. After the dilatancy point, micro cracks are reactivated gradually and interact with each other, which leads to crack coalescence and provides new seepage channels. The permeability increases gradually with increasing volumetric strain. It can be concluded from Figures 5(b), 5(d), 5(f), and 5(h) that there is a linear relationship between permeability and volumetric strain from dilatancy point to peak stress. At peak stress, permeability can increase by an order of magnitude compared with the initial permeability (see sample HM-3). After the peak stress, the seepage behavior changes from porous medium seepage to fractured medium seepage. In this stage, the permeability changes greatly, which is beyond the scope of this study.

According to tests results, the permeability evolution of Beishan granite in respect to volumetric strain can be roughly divided into two stages before reaching the peak stress, as shown in Figure 6. For the fractured medium seepage in the post peak stage, it is not possible to predict permeability just by volumetric strain. Before the dilatancy threshold $\sigma_{\text {cd }}$, permeability decreases with decreasing volumetric strain. It can be approximately expressed as linear relationship, and the linear coefficient is set to $K_{1}$. From dilatancy threshold $\sigma_{\text {cd }}$ to peak stress $\sigma_{\mathrm{c}}$, permeability increases linearly with increasing volumetric strain. The correlation coefficients (see Figure 5) 


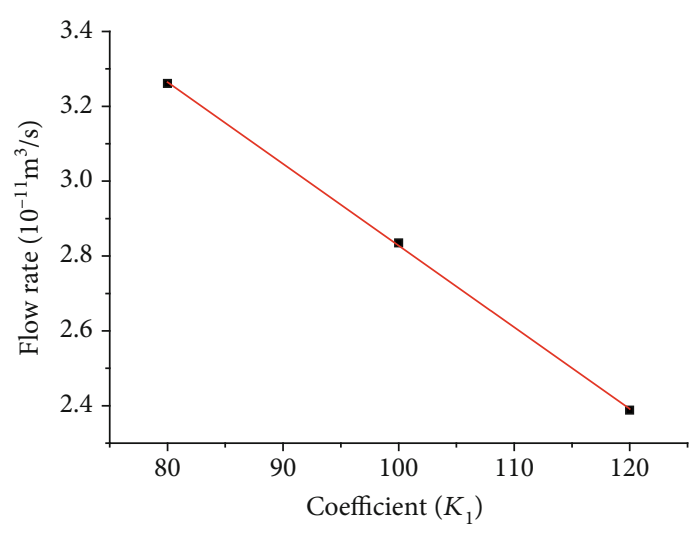

(a)

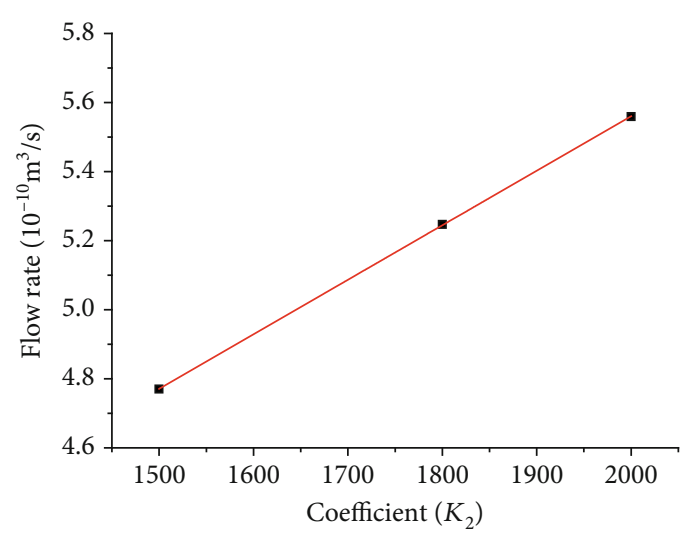

(b)

FIgURE 9: Flow rates and corresponding coefficients: (a) $K_{1}$ and (b) $K_{2}$.

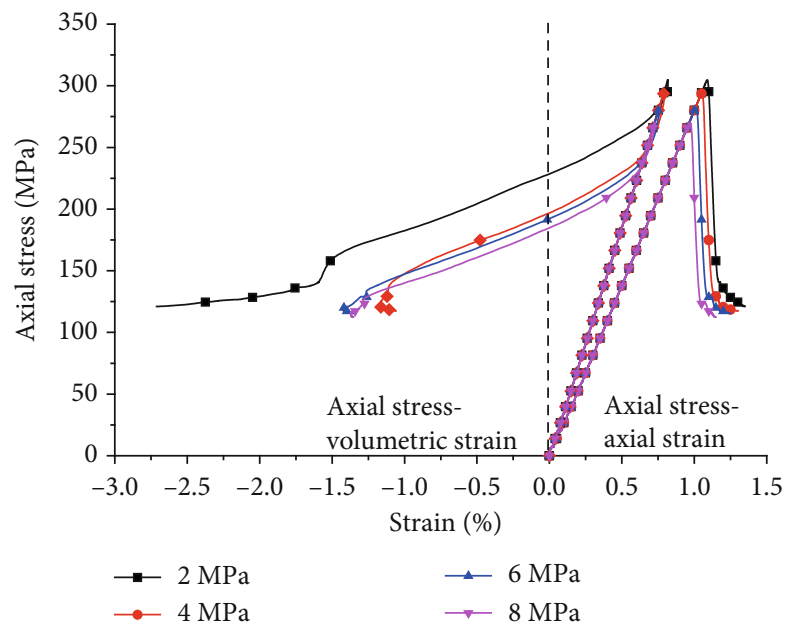

FIGURE 10: Simulated stress-strain curves for different pore pressures under $20 \mathrm{MPa}$ confining pressure.

confirm the correctness of linear fitting, and the linear coefficient is set to $K_{2}$. The relationships can be expressed by

$$
\left\{\begin{array}{l}
k=k_{0}\left(1+K_{1} \varepsilon_{v}\right) 0<\sigma_{1}<\sigma_{c d}, \\
k=k_{0}\left(1+K_{2} \varepsilon_{v}\right) \sigma_{c d}<\sigma_{1}<\sigma_{c}
\end{array}\right.
$$

where $k_{0}$ initial permeability $\left(\mathrm{m}^{2}\right)$ and $\varepsilon_{v}$ volumetric strain. It can be deduced from test data that $K_{2}$ is much greater than $K_{1}$.

\section{HM Coupled Simulations}

5.1. Model Description and Setup. In order to study the stress strain state inside the specimen, a heterogeneous cylindrical model with $50 \mathrm{~mm}$ in diameter and $100 \mathrm{~mm}$ in length is established in the explicit Finite Difference code FLAC ${ }^{3 \mathrm{D}}$ as shown in Figure 7. The model has 96000 zones and 100521 gridpoints. For the HM coupled simulations, the confining pressure is set to $20 \mathrm{MPa}$. A compressive displacement rate of $5 \mathrm{e}-8 \mathrm{~m} / \mathrm{step}$ is assigned on the top and bottom faces of the model. Permeable boundaries are applied at the top and bottom of the model. The pore pressure is fixed on the top

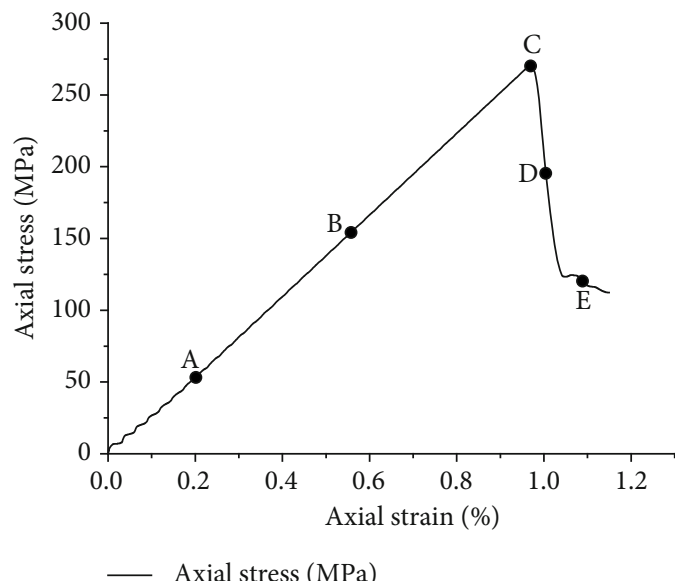

FIGURE 11: Simulated stress-strain curve for pore pressure of $8 \mathrm{MPa}$ under confining pressure of $20 \mathrm{MPa}$.

and bottom of the model to simulate constant fluid pressure. A strain-softening model is used for mechanics, and an isotropic Darcy model is used for the fluid flow. All input parameters are listed in Tables 4 and 5. And the parameters in Tables 4 and 5 are consistent with the HM coupled test.

5.2. Determination of Linear Correlation Coefficients. According to Section 4.3, the permeability has a linear relationship with volumetric strain. And volumetric strain of elements can be directly obtained in FLAC ${ }^{3 \mathrm{D}}$. Therefore, the permeability is updated during the numerical simulation. However, the linear relationships cannot be applied to describe the permeability evolution of the elements directly. Therefore, the linear coefficients need to be calibrated by several numerical simulations [41].

First, simulation of the conventional triaxial compression (CTC) test under confining pressure of $20 \mathrm{MPa}$ is conducted. A compressed numerical model (see Figure 8(a)) before the dilatancy threshold is chosen to determine the linear coefficient $K_{1}$, and a damaged numerical model beyond the dilatancy threshold (see Figure 8(b)) is chosen to determine the linear coefficient $K_{2}$. The initial permeability is set as 2.58 


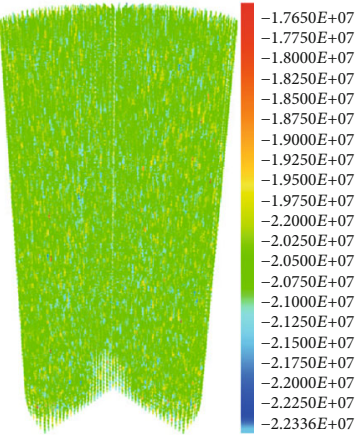

(a)

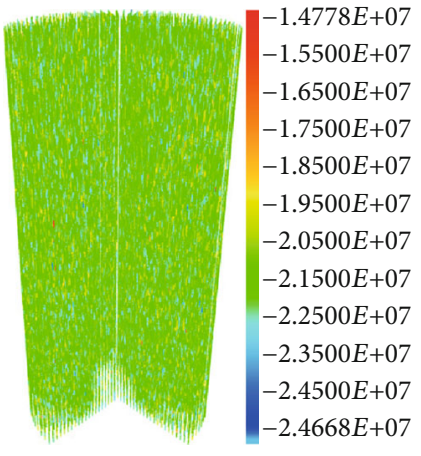

(b)

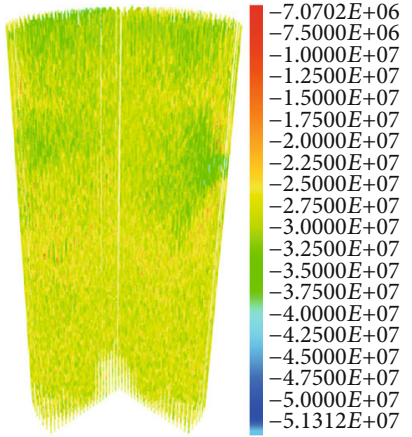

(c)

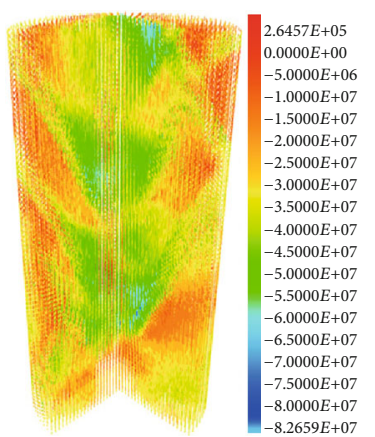

(d)

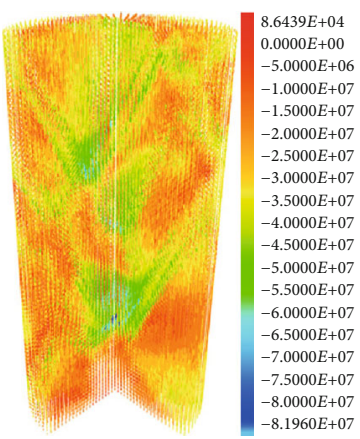

(e)

Figure 12: Evolution of maximum stress tensor $(\mathrm{Pa})$ for simulated HM coupled test: (a) initial compressed stage, (b) elastic stage, (c) peak stress point, (d) stress drop stage, and (e) residual stage.

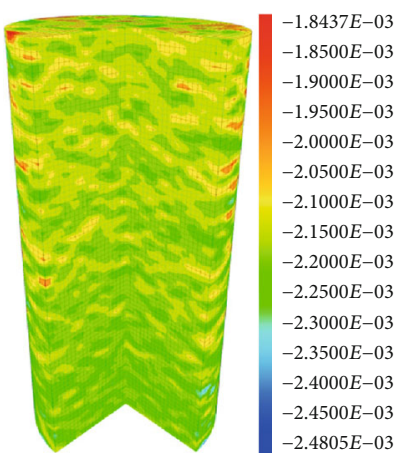

(a)

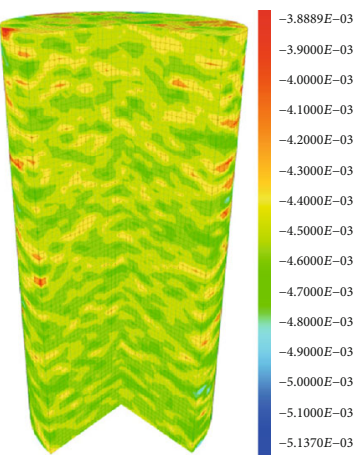

(b)

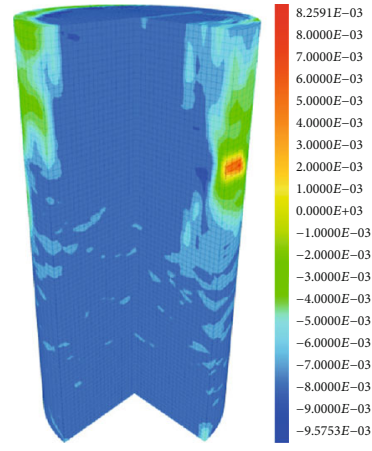

(c)

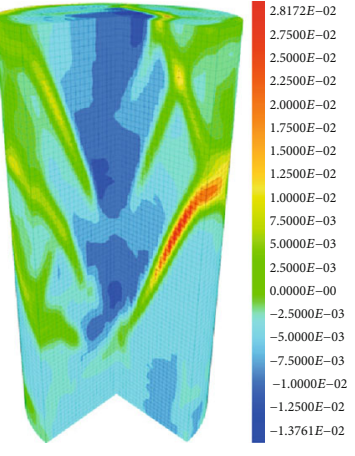

(d)

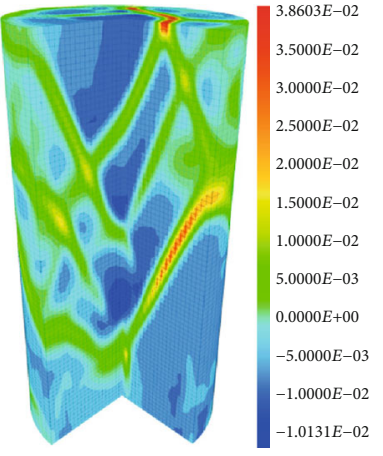

(e)

FIGURE 13: Evolution of volumetric strain for simulated HM coupled test: (a) initial compressed stage, (b) elastic stage, (c) peak stress point, (d) stress drop stage, and (e) residual stage. 


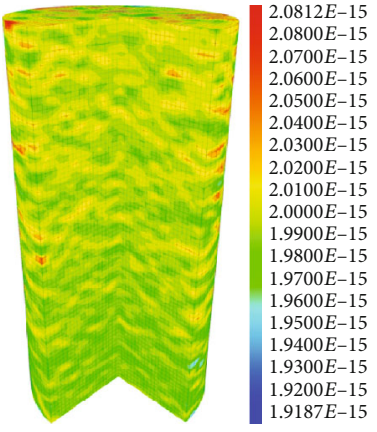

(a)

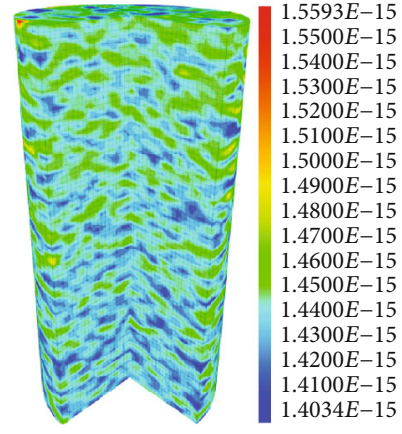

(b)

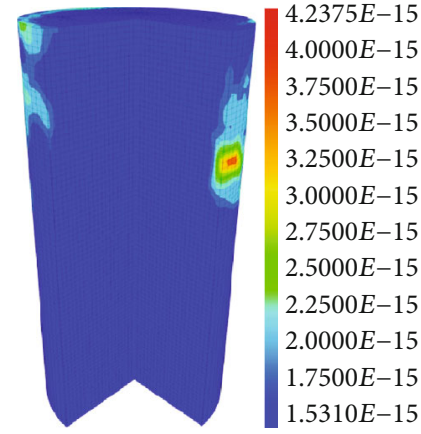

(c)

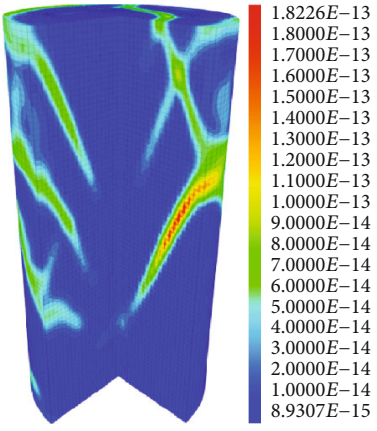

(d)

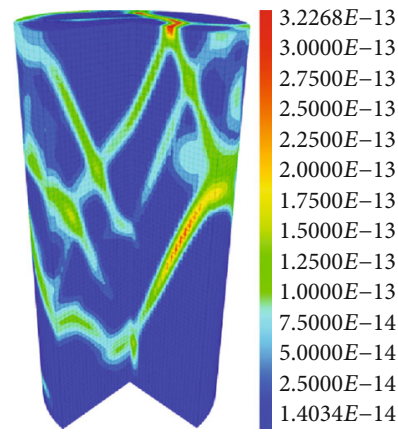

(e)

FIgURE 14: Evolution of permeability $\left(10^{-3} \mathrm{~m}^{2}\right)$ for simulated HM coupled test: (a) initial compressed stage, (b) elastic stage, (c) peak stress point, (d) stress drop stage, and (e) residual stage.

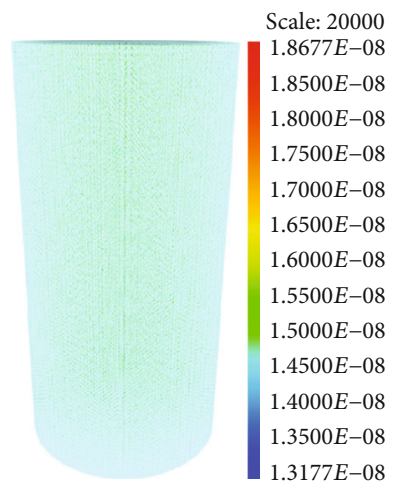

(a)

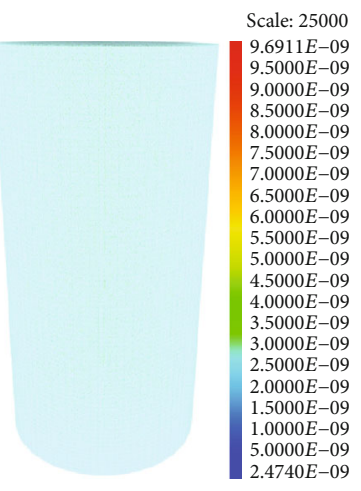

(b)

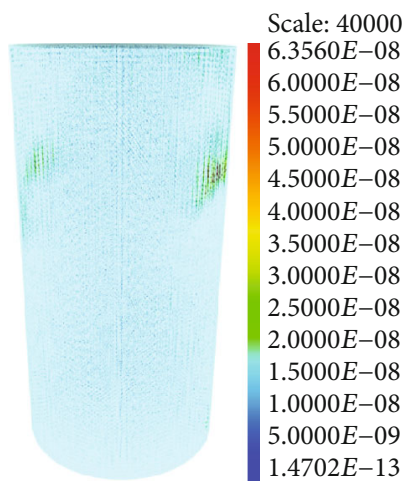

(c)

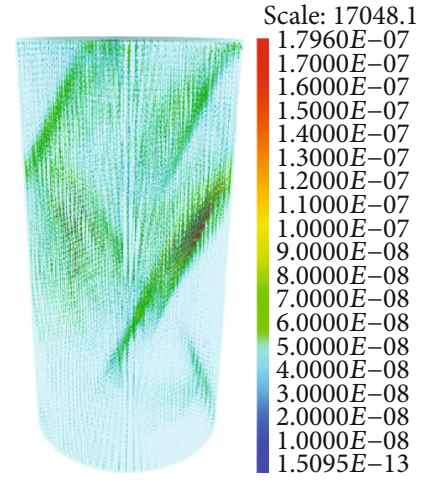

(d)

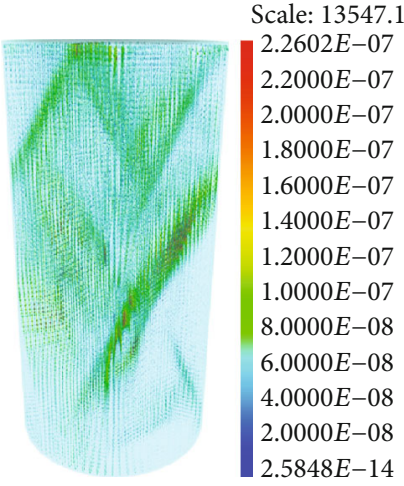

(e)

Figure 15: Evolution of discharge vectors (m/s) for simulated HM coupled test: (a) initial compressed stage, (b) elastic stage, (c) peak stress point, (d) stress drop stage, and (e) residual stage. 


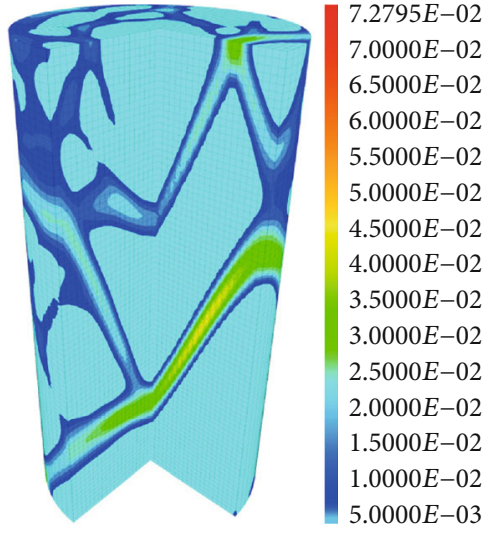

(a)

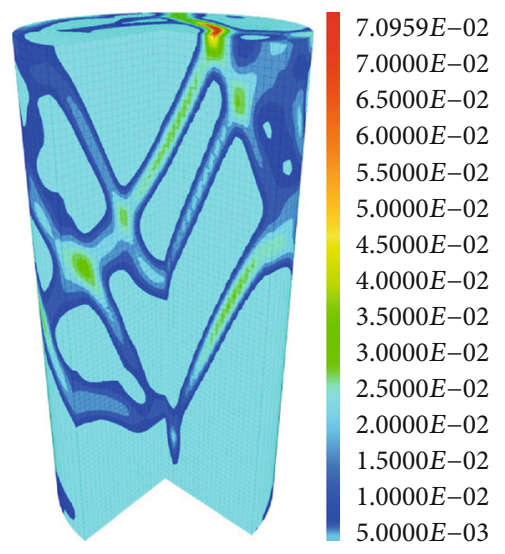

(c)

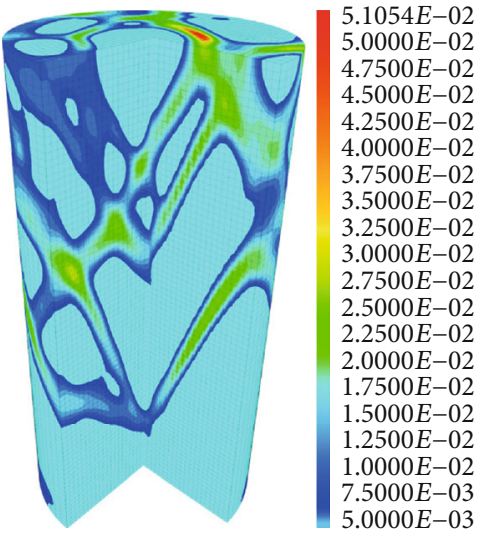

(b)

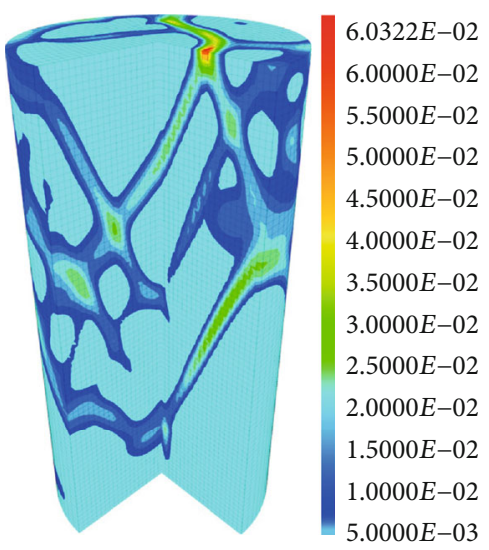

(d)

FIGURE 16: Volumetric strain $\left(\varepsilon_{v}>0.5 \%\right)$ at stage e under different fluid pressures: (a) pore pressure of $2 \mathrm{MPa}$, (b) pore pressure of $4 \mathrm{MPa}$, (c) pore pressure of $6 \mathrm{MPa}$, and (d) pore pressure of $8 \mathrm{MPa}$.

$\times 10^{-18} \mathrm{~m}^{2}$. The two models are used to simulate steady flow with different linear coefficients, and the results are shown in Figure 9. According to the flow rate, $K_{1}=80$ and $K_{2}=1700$ fit the lab results.

5.3. HM Coupled Simulation Results. The proposed permeability evolution rule (Equation (3)) is implemented into FLAC $^{3 \mathrm{D}}$. The pore pressures correspond to the HM coupling tests. Figure 10 shows stress-strain curves obtained from simulations. Taking the pore pressure of $8 \mathrm{MPa}$ as an example, the deformation and permeability evolution for different observation points (marked in Figure 11) are shown in Figures 12-15.

Some conclusions can be drawn from the numerical simulations. In the quasi elastic stage (points a and b), the stress state is nearly homogeneous; volumetric strain decreases with increasing axial stress, and all elements are compressed; permeability is decreasing and fluid flow is restricted. In brief, there is no damage at this stage. At the peak stress (point c), the stress distribution is no longer uniform; volumetric strain increases especially close to the model boundary; therefore, permeability and flow rate increase near the model boundary. During the stress drop (point e), local tensile stresses appear; volumetric strain increases rapidly and forms serval shear bands, which develop from the model boundary to the inside.
And it provides several seepage channels with high permeability for fluid flow. In the residual stage (point e), the tensile stress area expands; the volumetric strain bands become wider and interact with each other.

The macroscopic fracture patterns for samples under different pore pressures are shown in Figure 16. With the increase of pore pressure, the volumetric strain band channels increase. In other words, macroscopic fractures become pronounced with increasing pore pressure. It indicates that the pore pressure accelerates rock degradation during HM coupling.

\section{Conclusion}

HM coupled tests are carried out on Beishan granite under different pore pressures. The permeability evolution is studied. And numerical simulations are conducted to study the stress state and deformation process. Based on the results, the following conclusions can be drawn.

Before dilatancy, the initial pressure difference $\left(\triangle P_{0}\right)$ has little influence on permeability measurement by using the transient pulse method. However, after dilatancy, the permeability increases with the increasing initial pressure difference. Overall, the permeability evolution trends are the same. 
The initial permeability of Beishan granite maintains at the order $10^{-18} \mathrm{~m}^{2}$ under the confining pressure $20 \mathrm{MPa}$. In the initial loading phase, the permeability shows a relatively large reduction. Then, the permeability almost keeps constant. From onset of dilatancy to peak stress, the permeability increases linearly with the volumetric strain. A rule of relating permeability evolution with volumetric strain is proposed.

The simulation results show that the damaged zone first appears close to the model boundary and then extends to the inside, forming local high volumetric strain areas. And it provides seepage channels for fluid flow. The macroscopic fracture patterns indicate that pore pressure accelerates rock degradation during HM coupling.

In the future, more tests are needed for further investigating permeability evolution and fracturing characteristics of Beishan granite subjected to different confining stresses and pore pressures.

\section{Data Availability}

The data used to support the findings of this study are available from the corresponding author upon request.

\section{Conflicts of Interest}

The authors declare that they have no competing financial interests or personal relationships that could have influenced the work reported in this paper.

\section{Acknowledgments}

This work was supported by the Major Program of Shandong Province Natural Science Foundation (ZR2018ZA0603) and the National Natural Science Foundation of China (51674266).

\section{References}

[1] J. Wang, "High-level radioactive waste disposal in China: update 2010," Journal of Rock Mechanics and Geotechnical Engineering, vol. 2, no. 1, pp. 1-11, 2010.

[2] J. Wang, "On area-specific underground research laboratory for geological disposal of high-level radioactive waste in China," Journal of Rock Mechanics and Geotechnical Engineering, vol. 6, no. 2, pp. 99-104, 2014.

[3] S. Peng and A. M. Johnson, "Crack growth and faulting in cylindrical specimens of Chelmsford granite," International Journal of Rock Mechanics and Mining Science and Geomechanics Abstracts, vol. 9, no. 1, pp. 37-86, 1972.

[4] P. Tapponnier and W. F. Brace, "Development of stressinduced microcracks in Westerly granite," International Journal of Rock Mechanics and Mining Science and Geomechanics Abstracts, vol. 13, no. 4, pp. 103-112, 1976.

[5] M. Oda, T. Katsube, and T. Takemura, "Microcrack evolution and brittle failure of Inada granite in triaxial compression tests at $140 \mathrm{MPa}$," Journal of Geophysical Research, vol. 107, no. B10, pp. ECV 9-1-ECV 9-17, 2002.

[6] L. Jian-po, L. Yuan-hui, X. Shi-da, X. Shuai, and J. Chang-yu, "Cracking mechanisms in granite rocks subjected to uniaxial compression by moment tensor analysis of acoustic emission,"
Theoretical and Applied Fracture Mechanics, vol. 75, pp. 151$159,2015$.

[7] Y. H. Huang, S. Q. Yang, P. G. Ranjith, and J. Zhao, "Strength failure behavior and crack evolution mechanism of granite containing pre-existing non-coplanar holes: experimental study and particle flow modeling," Computers and Geotechnics, vol. 88, pp. 182-198, 2017.

[8] X. Cai, Z. Zhou, L. Tan, H. Zang, and Z. Song, "Fracture behavior and damage mechanisms of sandstone subjected to wettingdrying cycles," Engineering Fracture Mechanics, vol. 234, p. 107109, 2020.

[9] K. Suzuki, M. Oda, M. Yamazaki, and T. Kuwahara, "Permeability changes in granite with crack growth during immersion in hot water," International Journal of Rock Mechanics and Mining Science, vol. 35, no. 7, pp. 907-921, 1998.

[10] S. C. Yuan and J. P. Harrison, "A review of the state of the art in modelling progressive mechanical breakdown and associated fluid flow in intact heterogeneous rocks," International Journal of Rock Mechanics and Mining Science, vol. 43, no. 7, pp. 1001-1022, 2006.

[11] Y. Chitrala, C. Moreno, C. Sondergeld, and C. Rai, “An experimental investigation into hydraulic fracture propagation under different applied stresses in tight sands using acoustic emissions," Journal of Petroleum Science and Engineering, vol. 108, pp. 151-161, 2013.

[12] G. Liu, J. Peng, Z. Zhang, Z. Wang, and Y. Yang, "Numerical investigation of fluid-driven crack propagation and coalescence in granite specimen with two pre-existing flaws," Journal of Natural Gas Science and Engineering, vol. 75, p. 103132, 2020.

[13] W. F. Brace, J. B. Walsh, and W. T. Frangos, "Permeability of granite under high pressure," Journal of Geophysical Research, vol. 73, no. 6, pp. 2225-2236, 1968.

[14] M. D. Zoback and J. D. Byerlee, "The effect of microcrack dilatancy on the permeability of westerly granite," Journal of Geophysical Research, vol. 80, no. 5, pp. 752-755, 1975.

[15] T. Kiyama, H. Kita, Y. Ishijima, T. Yanagidani, K. Aoki, and T. Sato, "Permeability in anisotropic granite under hydrostatic compression and triaxial compression including post-failure region," in 2nd North American Rock Mechanics Symposium, American Rock Mechanics Association, 1996.

[16] L. Liu, W. Y. Xu, H. L. Wang, W. Wang, and R. B. Wang, "Permeability evolution of granite gneiss during triaxial creep tests," Rock Mechanics and Rock Engineering, vol. 49, no. 9, pp. 3455-3462, 2016.

[17] Y. Chen, "Permeability evolution in granite under compressive stress condition," Geotechnical and Geological Engineering, vol. 36, no. 1, pp. 641-647, 2018.

[18] H. Yi, H. Zhou, R. Wang, D. Liu, and J. Ding, “On the relationship between creep strain and permeability of granite: experiment and model investigation," Energies, vol. 11, no. 10, p. 2859, 2018.

[19] J. Heiland and S. Raab, "Experimental investigation of the influence of differential stress on permeability of a lower permian (rotliegend) sandstone deformed in the brittle deformation field," Physics and Chemistry of the Earth Part A, vol. 26, no. 12, pp. 33-38, 2001.

[20] A. K. M. B. Alam, M. Niioka, Y. Fujii, D. Fukuda, and J. I. Kodama, "Effects of confining pressure on the permeability of three rock types under compression," International Journal of Rock Mechanics and Mining Sciences, vol. 65, pp. 49-61, 2014. 
[21] Y. Zhang, Z. B. Liu, W. Y. Xu, and J. F. Shao, "Change in the permeability of clastic rock during multi-loading triaxial compressive creep tests," Géotechnique Letters, vol. 5, no. 3, pp. 167-172, 2015.

[22] C. F. Tsang, L. Jing, O. Stephansson, and F. Kautsky, “The DECOVALEX III project: a summary of activities and lessons learned," International Journal of Rock Mechanics and Mining Sciences, vol. 42, no. 5-6, pp. 593-610, 2005.

[23] C. F. Tsang, O. Stephansson, L. Jing, and F. Kautsky, "DECOVALEX Project: from 1992 to 2007," Environmental Geology, vol. 57, no. 6, pp. 1221-1237, 2009.

[24] C. A. Tang, L. G. Tham, P. K. K. Lee, T. H. Yang, and L. C. Li, "Coupled analysis of flow, stress and damage (FSD) in rock failure," International Journal of Rock Mechanics and Mining Sciences, vol. 39, no. 4, pp. 477-489, 2002.

[25] J. Rutqvist, Y. S. Wu, C. F. Tsang, and G. Bodvarsson, "A modeling approach for analysis of coupled multiphase fluid flow, heat transfer, and deformation in fractured porous rock," International Journal of Rock Mechanics and Mining Sciences, vol. 39, no. 4, pp. 429-442, 2002.

[26] X. Tan and H. Konietzky, "Numerical simulation of permeability evolution during progressive failure of Aue granite at the grain scale level," Computers and Geotechnics, vol. 112, pp. 185-196, 2019.

[27] Y. L. Lu, D. Elsworth, and L. G. Wang, "Microcrack-based coupled damage and flow modeling of fracturing evolution in permeable brittle rocks," Computers and Geotechnics, vol. 49, pp. 226-244, 2013.

[28] J. Heiland, "Laboratory testing of coupled hydro-mechanical processes during rock deformation," Hydrogeology Journal, vol. 11, no. 1, pp. 122-141, 2003.

[29] X. Tan, Hydro-mechanical coupled behavior of brittle rocks, Dissertation, Technische Universität Bergakademie Freiberg, Freiberg, Germany, 2013.

[30] R. L. Kranzz, A. D. Frankel, T. Engelder, and C. H. Scholz, "The permeability of whole and jointed Barre granite," International Journal of Rock Mechanics and Mining Science and Geomechanics Abstracts, vol. 16, no. 4, pp. 225-234, 1979.

[31] R. L. Kranz, J. S. Saltzman, and J. D. Blacic, "Hydraulic diffusivity measurements on laboratory rock samples using an oscillating pore pressure method," International Journal of Rock Mechanics and Mining Science and Geomechanics Abstracts, vol. 27, no. 5, pp. 345-352, 1990.

[32] J. B. Walsh and W. F. Brace, "The effect of pressure on porosity and the transport properties of rock," Journal of Geophysical Research, vol. 89, no. B11, pp. 9425-9431, 1984.

[33] H.-D. Chen, C. Yuan-Ping, H.-X. Zhou, and W. Li, "Damage and permeability development in coal during unloading," Rock Mechanics and Rock Engineering, vol. 46, no. 6, pp. 1377-1390, 2013.

[34] C. E. Fairhurst and J. A. Hudson, "Discussion," International Journal of Rock Mechanics \& Mining Science, vol. 36, no. 3, pp. 279-289, 1999.

[35] X. G. Zhao, M. Cai, J. Wang, and L. K. Ma, "Damage stress and acoustic emission characteristics of the Beishan granite," International Journal of Rock Mechanics and Mining Science, vol. 64, no. 12, pp. 258-269, 2013.

[36] X. G. Zhao, J. Wang, F. Chen et al., "Experimental investigations on the thermal conductivity characteristics of Beishan granitic rocks for China's HLW disposal," Tectonophysics, vol. 683 , pp. 124-137, 2016.
[37] H. W. Zhou, Z. H. Wang, C. S. Wang, and J. F. Liu, "On acoustic emission and post-peak energy evolution in Beishan granite under cyclic loading," Rock Mechanics and Rock Engineering, vol. 52, no. 1, pp. 283-288, 2019.

[38] L. Chen, J. Liu, C. P. Wang, J. Liu, R. Su, and J. Wang, "Characterization of damage evolution in granite under compressive stress condition and its effect on permeability," International Journal of Rock Mechanics and Mining Science, vol. 71, pp. 340-349, 2014.

[39] S. Q. Yang, H. W. Jing, and S. Y. Wang, "Experimental investigation on the strength, deformability, failure behavior and acoustic emission locations of red sandstone under triaxial compression," Rock Mechanics and Rock Engineering, vol. 45, no. 4, pp. 583-606, 2012.

[40] H. W. Zhou, Z. H. Wang, W. G. Ren, Z. L. Liu, and J. F. Liu, "Acoustic emission based mechanical behaviors of Beishan granite under conventional triaxial compression and hydromechanical coupling tests," International Journal of Rock Mechanics and Mining Science, vol. 123, p. 104125, 2019.

[41] X. Tan, H. Konietzky, and T. Frühwirt, "Laboratory observation and numerical simulation of permeability evolution during progressive failure of brittle rocks," International Journal of Rock Mechanics and Mining Sciences, vol. 68, pp. 167-176, 2014. 